\title{
Mesenteric phlebosclerosis
}

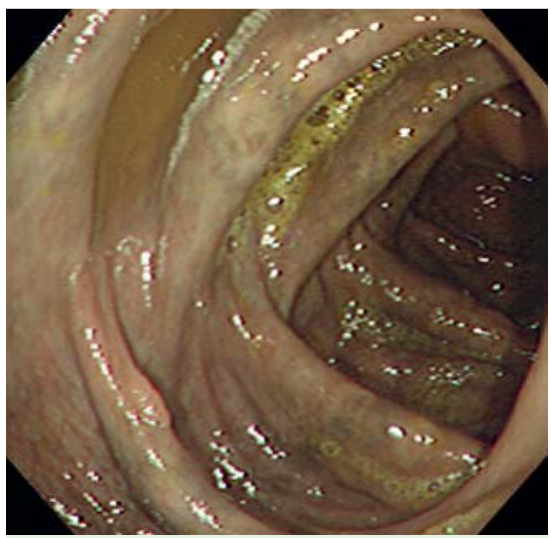

Fig. 1 Endoscopic view showing the dark-purple mucosal surface.

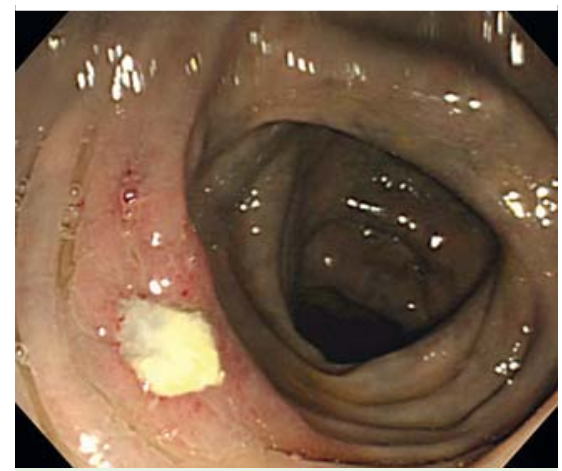

Fig. 2 Endoscopic view showing the multiple mucosal ulcerations.

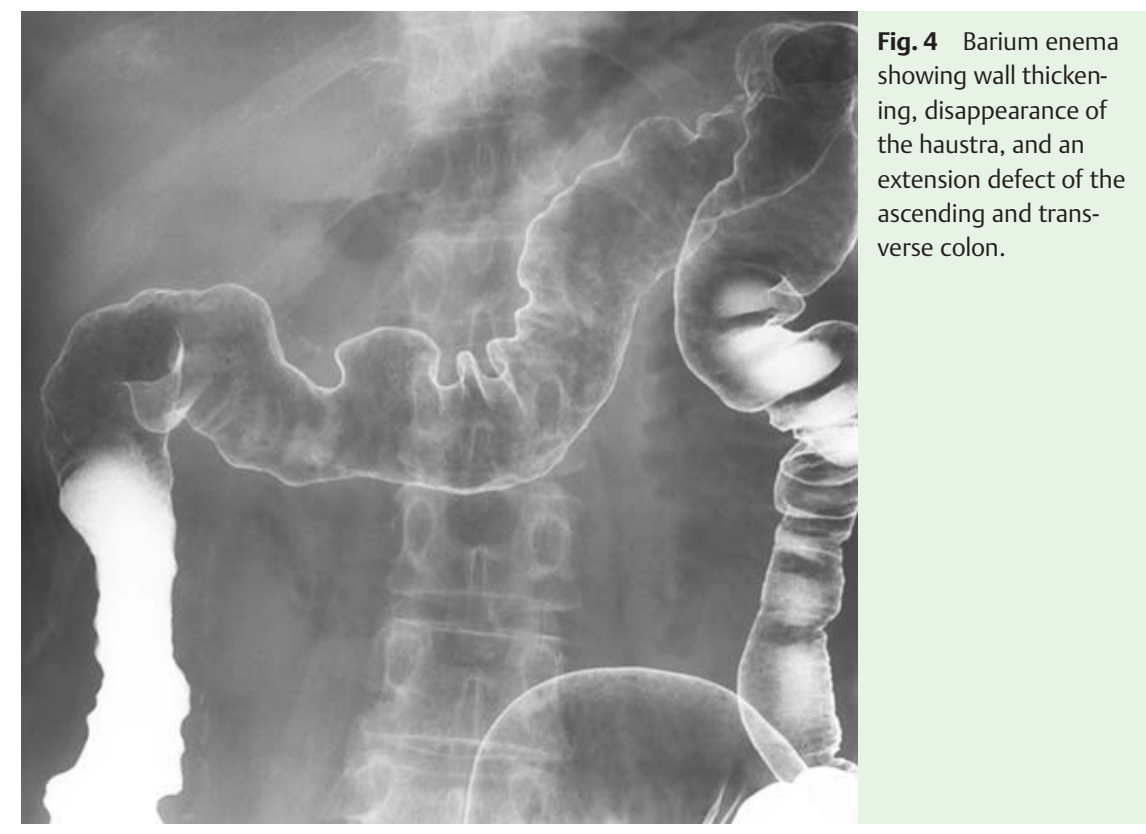

Phlebosclerosis is a rare cause of chronic mesenteric ischemia, and is characterized by thickening of the colonic wall with calcification of the affected veins. Phlebosclerosis as a disease entity has been recently proposed by Iwashita et al [1]. Fewer than 100 cases have been reported to date, and most are from Japan. We present a case of chronic ischemic colonic lesions caused by phlebosclerosis.

A 58-year-old woman was admitted to our hospital for colonoscopy. At the first colonoscopy, the mucosal surface from the ileocecal junction to the transverse colon was seen to be dark purple in color ( $\bullet$ Fig. 1). Since then, the patient has been under regular colonoscopic follow-up (about one or two times a year). At 6 years after the first presentation, we noted multiple mucosal ulcerations extending from the ascending to the transverse colon ( $\bullet$ Fig. 2), and at 8 years after the first presentation, the colonoscopic findings included scars and ulcers ( $\bullet$ Fig. 3). Barium enema showed wall thickening, disappearance of the haustra, and an extension defect in the ascending and transverse colon (Fig. 4). Abdominal computed tomography showed patchy and linear calcifications in and around the colonic wall ( Fig.5). The histopathologic findings were compatible with ischemic colitis.

The pathogenesis of phlebosclerosis remains unclear. More case reports and further research are needed to clarify the etiology of phlebosclerosis.

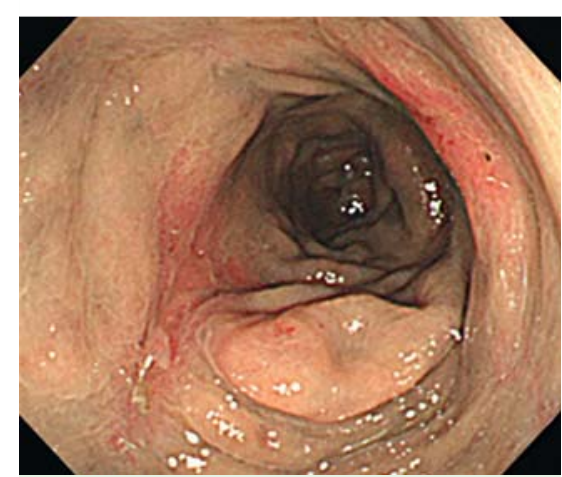

Fig. 3 Endoscopic view showing ulcers and scarring.

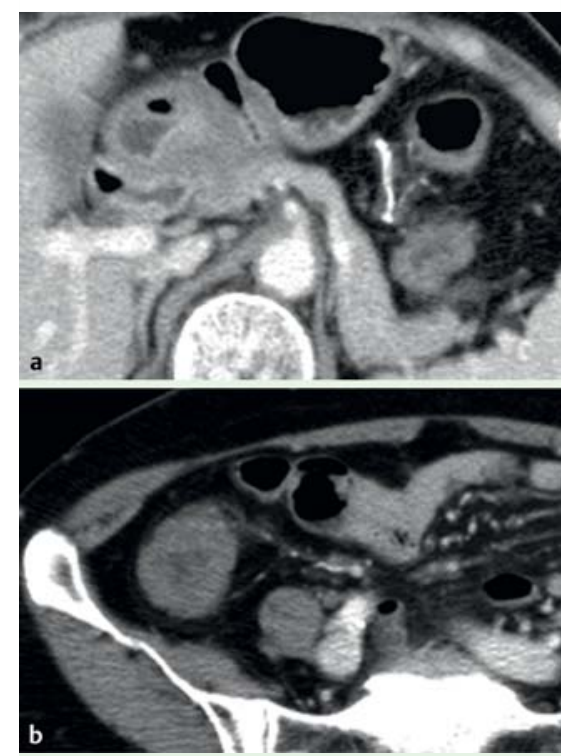

Fig. 5 a, b Computed tomography (CT) scans showing patchy and linear calcifications in and around the colonic wall.

\section{Competing interests: None}

Endoscopy_UCTN_Code_CCL_1AD_2AF

A. Oshima, S. Ito, Y. Abe, T. Uchiyama, H. lida, H. Endo, K. Hosono, Y. Sakamoto, K. Fujita, M. Yoneda, H. Takahashi, T. Koide, C. Tokoro, A. Goto, M. Inamori, N. Kobayashi, K. Kubota, S. Saito, A. Nakajima

Gastroenterology Division, Yokohama City University School of Medicine, Yokohama, Japan 


\section{References}

1 Iwashita A, Yao T, Schlemper RJ et al. Mesenteric phlebosclerosis: a new disease entity causing ischemic colitis. Dis Colon Rectum 2003; 46: 209-220
Bibliography

DOI $10.1055 / \mathrm{s}-0029-1244147$

Endoscopy 2010; 42: E156-E157

(c) Georg Thieme Verlag KG Stuttgart · New York . ISSN 0013-726X
Corresponding author

\section{Inamori, MD, PhD}

Gastroenterology Division

Yokohama City University School of Medicine

3-9 Fukuura

Kanazawa-ku

Yokohama 236-0004

Japan

Fax: +81-45-7843546

inamorim@med.yokohama-cu.ac.jp 